\title{
A Monostyryl-boradiazaindacene (BODIPY) Derivative as Colorimetric and Fluorescent Probe for Cyanide Ions
}

2008

Vol. 10, No. 3

$461-464$

\author{
Zeynep Ekmekci, ${ }^{\dagger}$ M. Deniz Yilmaz, ${ }^{\dagger, \S}$ and Engin U. Akkaya ${ }^{\star, \neq}$ \\ Department of Chemistry, Middle East Technical University, \\ Ankara, Turkey, TR-06531, and Department of Chemistry, \\ Bilkent University, Ankara, Turkey, TR-06800
}

eua@fen.bilkent.edu.tr

Received November 21, 2007

\section{ABSTRACT}

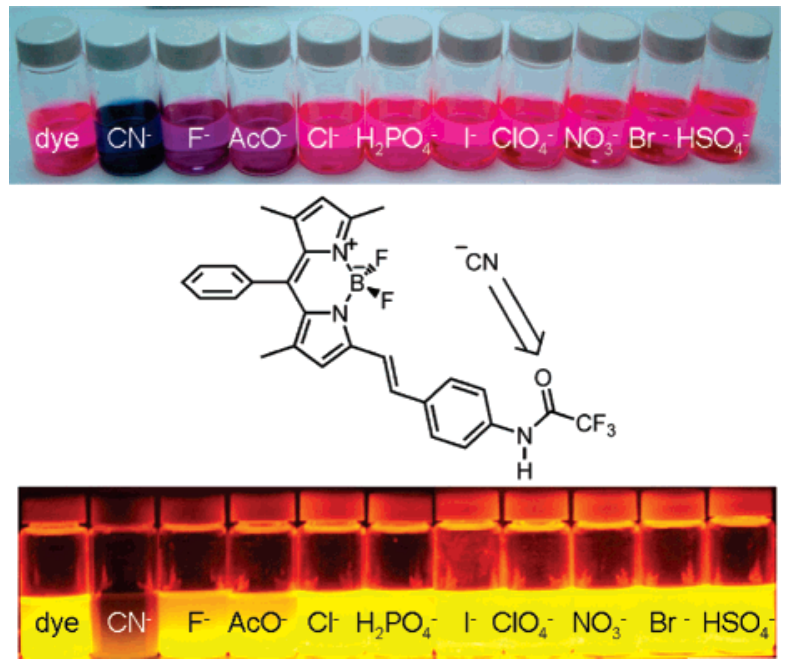

We developed a novel boradiazaindacene derivative to detect cyanide ions in solution at micromolar concentrations. This structurally simple chemosensor displays a large decrease in emission intensity and a reversible color change from red to blue on contact with cyanide ions. Highly fluorescent polymeric films can be obtained by doping with the chemosensor. Such polymeric materials can be used for the sensing of the cyanide ions in polymer matrices.

The development of selective optical signaling systems for anions is an emerging field of research in supramolecular photochemistry. ${ }^{1}$ Cyanide is one of the most lethal poisons known. A significant proportion of fatalities among fire victims is due to cyanide poisoning, as blood cyanide concentrations reach a level of 23-26 $\mu \mathrm{M}^{2}$ Furthermore, cyanide concentrations in drinking water have to be lower

\footnotetext{
$\dagger$ Middle East Technical University.

Bilkent University.

§ Present address: Laboratories of Supramolecular Chemistry and Technology and Molecular Nanofabrication, MESA+ Institute for Nanotechnology, University of Twente, P. O. Box 217, 7500 AE, Enschede,
} The Netherlands. than $1.9 \mu \mathrm{M} .{ }^{3}$ With these considerations, a number of promising fluorescent probes and organic dyes have been reported

(1) (a) Antonisse, M. M. G.; Reinhoudt, D. N. Chem. Commun. 1998 443. (b) Snowden, T. S.; Anslyn, E. V. Curr. Opin. Chem. Biol. 1999, 3 , 740. (c) Beer, P. D.; Gale, P. A. Angew. Chem., Int. Ed. 2001, 40, 486516. (d) Amendola, V.; Esteban-Gómez, D.; Fabbrizzi, L.; Licchelli, M. Acc. Chem. Res. 2006, 39, 343-353. (e) Martínez-Máñez, R.; Sancenón, F. Coord. Chem. Rev. 2006, 250, 3081-3093.

(2) (a) Ishii, A.; Seno, H.; Watanabe-Suzuki, K.; Suzuki, O.; Kumazawa, T. Anal. Chem. 1998, 70, 4873-4876. (b) Moriya, F.; Hashimoto, Y. J. Forensic Sci. 2001, 46, 1421-1425. (c) Kulig, K. W. Cyanide Toxicity; U.S. Department of Health and Human Services: Atlanta, GA, 1991. (d) Baskin, S. I.; Brewer, T. G. Medical Aspects of Chemical and Biological Warfare; Sidell, F. R., Takafuji, E. T., Franz, D. R, Eds.; TMM Publications: Washington, DC, 1997; pp 271-286. 
as optical sensors for cyanide ions. ${ }^{4}$ Most of them display color changes, but relatively few of them result in spectral shifts in both absorption and emission spectra. ${ }^{5}$

Boradiazaindacenes (BODIPY dyes) are well-known ${ }^{6}$ fluorophores with high quantum yields and large extinction coefficients, attracting considerable attention especially within the past few years in a variety of potential applications such as ion sensing and signaling, ${ }^{7}$ energy transfer cassettes, ${ }^{8}$ light-harvesting systems, ${ }^{9}$ fluorescent labeling of biomolecules, ${ }^{10}$ and as potential sensitizers in photodynamic therapy. ${ }^{11}$

Here, we report the design and synthesis of new boradiazaindacene (BODIPY)-based chemosensor for selective and sensitive reporting of cyanide ions. The structure and synthesis of compound $\mathbf{3}$ is depicted in Scheme 1. The target

Scheme 1. Structure and the Synthesis of the Chemosensor 3

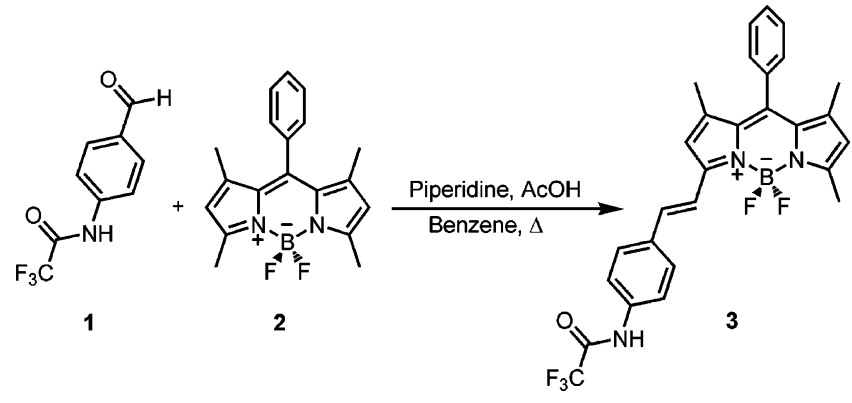

chemosensor $\mathbf{3}$ was prepared by Knoevenagel-type condensation of the known BODIPY dye $\mathbf{2}$ (which was synthesized by reacting benzoylchloride and 2,4-dimethylpyrrole under

(3) (a) Guidelines for Drinking-Water Quality; World Health Organization: Geneva, 1996. (b) Ullman's Encyclopedia of Industrial Chemistry, 6th ed; Wiley-VCH: New York, 1999.

(4) (a) Lakowicz, J. R. Principles of Fluorescence Spectroscopy, 2nd ed.; Kluwer/Academic Plenum Publishers: New York, 1997. (b) Lakowicz, J. R. Topics in Fluorescence Spectroscopy: Probe Design and Chemical Sensing; Plenum Press: New York, 1994; Vol. 4. (c) Anzenbacher, P.; Tyson, D. S.; Jursikova, K.; Castellano, F. N. J. Am. Chem. Soc. 2002 , 124, 6232-6233. (d) Badugu, R.; Lakowicz, J. R.; Geddes, C. D. J. Am. Chem. Soc. 2005, 127, 3635-3641.

(5) (a) Tomasulo, M.; Raymo, F. M. Org. Lett. 2005, 7, 4633-4636. (b) Tomasulo, M.; Sortino, S.; White, A. J. P.; Raymo, F. M. J. Org. Chem. 2006, 71, 744-753. (c) Chung, Y. M.; Raman, B.; Kim, D. S.; Ahn, K. H. Chem. Commun. 2006, 186-188. (d) Ros-Lis, J. V.; Martínez-Máñez, R.; Soto, J. Chem. Commun. 2005, 5260-5262. (e) Miyaji, H.; Sessler, J. L. Angew. Chem., Int. Ed. 2001, 40, 154-157. (f) Chen, C.-L.; Chen, Y.-H.; Chen, C.-Y.; Sun, S.-S. Org. Lett. 2006, 8, 5053-5056. (g) Yang, Y.-K.; Tae, J. Org. Lett. 2006, 8, 5721-5723.

(6) (a) Treibs, A.; Kreuzer, F.-H. Justus Liebigs Ann. Chem. 1968, 718 208-223. (b) Haugland, R. P. The Handbook. A Guide to Fluorescent Probes and Labeling Technologies, 10th ed.; Molecular Probes, Inc.: Eugene, OR, 2005.

(7) (a) Turfan, B.; Akkaya, E. U. Org. Lett. 2002, 4, 2857-2859. (b) Goze, C.; Ulrich, G.; Charbonnière, L.; Cesario, M.; Prangé, T.; Ziessel, R. Chem. Eur. J. 2003, 9, 3748-3755. (c) Gabe, Y.; Urano, Y.; Kikuchi, K.; Kojima, H.; Nagano, T. J. Am. Chem. Soc. 2004, 126, 3357-3367. (d) Rurack, K.; Kollmannsberger, M.; Resch-Genger, U.; Daub, J. J. Am. Chem. Soc. 2000, 122, 968-969. (e) Coskun, A.; Akkaya, E. U. J. Am. Chem. Soc. 2005, 127, 10464-10465. (f) Coskun, A.; Yilmaz, M. D.; Akkaya, E. U. Org. Lett. 2007, 9, 607-609.

(8) (a) Burghart, A.; Thoresen, L. H.; Chen, J.; Burgess, K.; Bergström, F.; Johansson, L. B.-A. Chem. Commun. 2000, 2203-2204. (b) Goze, C.; Ulrich, G.; Ziessel, R. Org. Lett. 2006, 8, 4445-4448. (c) Wan, C.-W. Burghart, A.; Chen, J.; Bergström, F.; Johansson, L. B.- $\AA$.; Wolford, M. F.; Kim, T. G.; Topp, M. R.; Hochstrasser, R. M.; Burgess, K. Chem. Eur. J. 2003, 9, 4430-4441. reflux in dichloromethane, followed by the addition of triethylamine and borontrifluoroetherate) and the corresponding aldehyde $\mathbf{1}$ in a Dean-Stark apparatus with azeotropic removal of water. The reactivity of the acidic 3- and/or 5-methyls on the boradiazaindacene core is now firmly established. ${ }^{7 e, f, 11,12}$ The reaction reached completion within $2 \mathrm{~h}$ with good isolated yields. The structure of $\mathbf{3}$ was confirmed by ${ }^{1} \mathrm{H} \mathrm{NMR},{ }^{13} \mathrm{C} \mathrm{NMR}$, and HRMS data (Supporting Information).

The treatment of compound 3 with $\mathrm{Bu}_{4} \mathrm{NCN}$ in acetonitrile resulted in the formation of a blue nonfluorescent solution, and the emission was restored on the addition of trifluoroacetic acid (Scheme 2). Further evidence of chemosensor-

Sche

Scheme 2. Suggested Mechanism for ON-OFF Switching within the Presence of $\mathrm{CN}^{-}$Ions


cyanide interaction was obtained by studying the ${ }^{1} \mathrm{H}$ NMR spectra which were recorded before and after the addition of tetrabutylammonium cyanide in acetonitrile- $d_{6}$ solution. Most of the aromatic and olefinic protons exhibited an upfield shift $(\sim 0.5 \mathrm{ppm})$ which is compatible with the proposed switching mechanism (Scheme 2 and Supporting Information).

The absorption spectral changes of $\mathbf{3}$ on addition of cyanide in acetonitrile are shown in Figure 1. The absorption band at $561 \mathrm{~nm}$ decreased, while a new band at $594 \mathrm{~nm}$ appeared. A clean isosbestic point of $571 \mathrm{~nm}$ indicated an interconversion into single discrete chemical species during the titration process. When the titration was repeated with different anions, such as $\mathrm{F}^{-}, \mathrm{Cl}^{-}, \mathrm{Br}^{-}, \mathrm{I}^{-}, \mathrm{AcO}^{-}, \mathrm{ClO}_{4}^{-}$, $\mathrm{H}_{2} \mathrm{PO}_{4}{ }^{-}, \mathrm{HSO}_{4}{ }^{-}$, and $\mathrm{NO}_{3}{ }^{-}$, it was evident that only cyanide ion produced a large spectral change in the absorption spectrum (33 nm bathochromic shift). The extinction coefficient of the chemosensor 3 at $561 \mathrm{~nm}$ is $83000 \mathrm{M}^{-1} \mathrm{~cm}^{-1}$ and $56400 \mathrm{M}^{-1} \mathrm{~cm}^{-1}$ at $594 \mathrm{~nm}$ for the $3-\mathrm{CN}^{-}$adduct.

(9) (a) Yilmaz, M. D.; Bozdemir, O. A.; Akkaya, E. U. Org. Lett. 2006 8, 2871-2873. (b) Goeb, S.; Ziessel, R. Org. Lett. 2007, 9, 737-740.

(10) Yee, M.; Fas, S. C.; Stohlmeyer, M. M.; Wandless, T. J.; Cimprich, K. A. J. Biol. Chem. 2005, 280, 29053-29059.

(11) Atilgan, S.; Ekmekci, S.; Dogan, A. L.; Guc, D.; Akkaya, E. U. Chem. Commun. 2006, 4398-4400.

(12) (a) Saki, N.; Dinc, N.; Akkaya, E. U. Tetrahedron 2006, 62, 2721 2725. (b) Dost, Z.; Atilgan, S.; Akkaya, E. U. Tetrahedron 2006, 62, 84848488. (c) Coskun, A.; Deniz, E.; Akkaya, E. U. Tetrahedron Lett. 2007, $48,5359-5361$. 


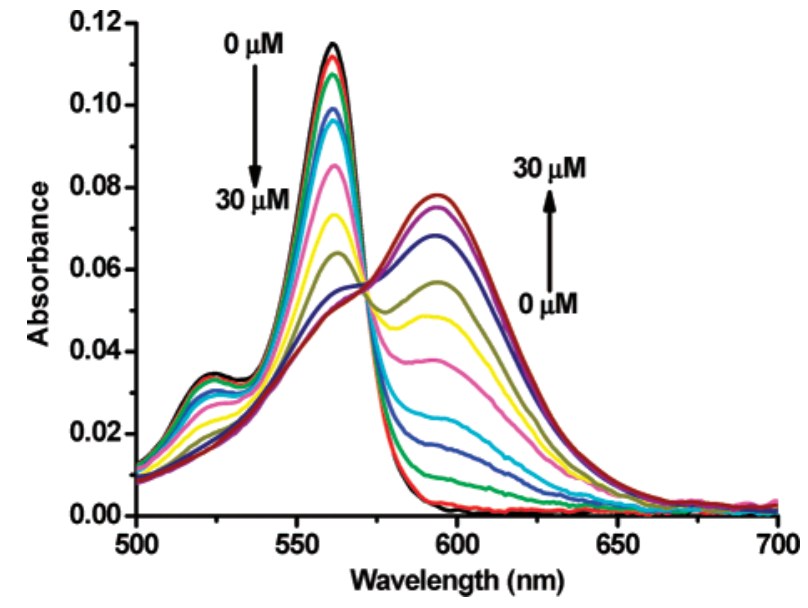

Figure 1. Absorption spectrum of the chemosensor $3(1.38 \mu \mathrm{M})$ to increasing concentrations of $\mathrm{CN}^{-}$in acetonitrile. Cyanide concentrations were varied in the following order: $0,2.5,3,5,6$, $10,15,16,18,20,30 \mu \mathrm{M}$.

Figure 2 shows the emission spectrum for compound $\mathbf{3}$ on addition of $\mathrm{CN}^{-}$. When excited at $560 \mathrm{~nm}$, the emission

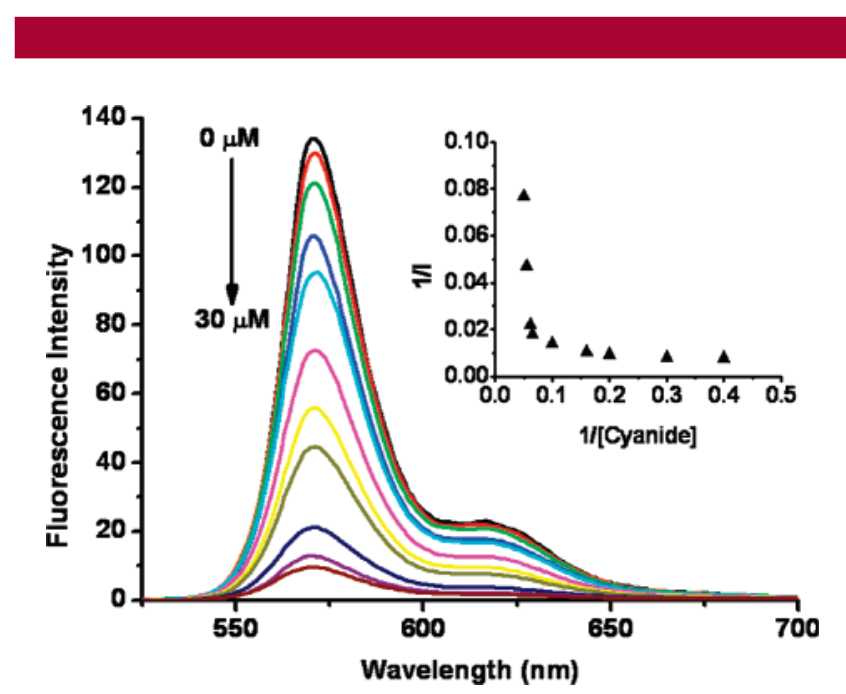

Figure 2. Change in the emission spectrum of the chemosensor 3 $(1.38 \mu \mathrm{M})$ in response to increasing concentrations of $\mathrm{CN}^{-}$in acetonitrile. Cyanide concentrations were varied in the following order: $0,2.5,3,5,6,10,15,16,18,20,30 \mu \mathrm{M}$. Excitation was at $560 \mathrm{~nm}$, with slit widths of $5 \mathrm{~nm}$. (Inset) Plot of fluorescence intensity at $571 \mathrm{~nm}$ vs number of equivalents of $\mathrm{CN}^{-}$.

intensity at $571 \mathrm{~nm}$ decreases 14 -fold on changing the concentration of $\mathrm{CN}^{-}$from 0 to $30 \mu \mathrm{M}$. From the ${ }^{1} \mathrm{H}$ NMR and emission spectra of $\mathbf{3}$, it is concluded that cyanide attacked the carbonyl group which activated by the strong electronwithdrawing effect of the trifluoromethyl group, and thus cyanohydrin formation in $\mathbf{3}$ took place. Quantum yields in acetonitrile are 0.27 for compound 3 and 0.01 for the $3-\mathrm{CN}^{-}$ complex. Quantum yields were determined using Rhodamine $6 \mathrm{G}$ as reference $\left(\Phi=0.95\right.$ in ethanol). ${ }^{13}$

Org. Lett., Vol. 10, No. 3, 2008
The anion selectivity of the optical response of the chemosensor $\mathbf{3}$ was also studied (Figure 3). It is obvious that

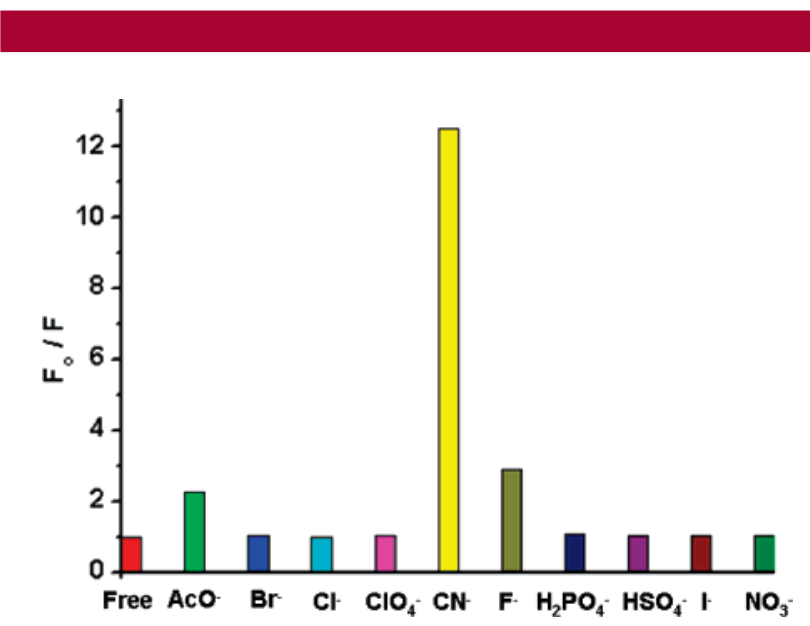

Figure 3. Anion selectivity of the chemosensor 3. Each anion is added at a concentration of $30 \mu \mathrm{M}$ to an acetonitrile solution of the dye $3(1.38 \mu \mathrm{M})$. The counterions are tetrabutylammonium. Excitation was at $560 \mathrm{~nm}$, with slit widths of $5 \mathrm{~nm}$.

the potential competitor anions, in particular fluoride, did not lead to significant fluorescence changes, whereas on $\mathrm{CN}^{-}$ addition at the same concentration $(30 \mu \mathrm{M})$, the emission ratio changed more than 10 -fold.

In order to demonstrate chemosensor-cyanide interaction in a polymer matrix, a poly(methyl methacrylate) polymer film doped with the compound $\mathbf{3}$ was prepared. Absorption and emission spectra of polymer film doped with $\mathbf{3}$ were obtained, and $10 \mathrm{~nm}$ bathochromic shifts were observed in absorption and emission maxima (for spectra, see Supporting Information). To prepare the polymer films, poly(methyl methacrylate) PMMA polymer (300 mg) was dissolved in dichloromethane, poured onto a clean glass surface, and doped with the compound 3 (1.5 mg, $0.5 \mathrm{wt} \%)$. The solvent was evaporated to dryness, and a homogeneous, highly fluorescent polymer film was obtained. This thin film was covered with a shadow mask including the $\mathrm{CN}^{-}$fingerprint. A solution containing tetrabutylammonium cyanide in acetonitrile $(1 \mathrm{mM})$ was sprayed onto the film, and the solvent was evaporated in air. A blue nonfluorescent image appeared on the regions exposed to cyanide ions (Figure 4). For the

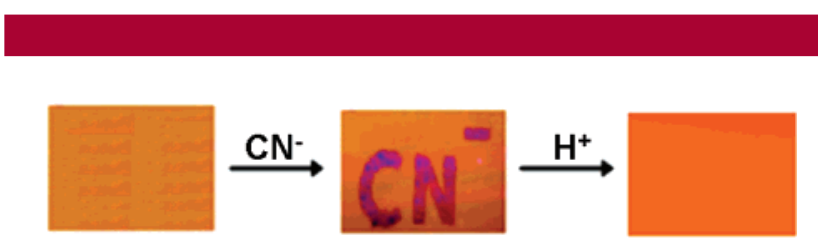

Figure 4. Fluorescence image of poly(methyl methacrylate) polymer sheets doped with chemosensor 3. The polymer film on glass was irradiated with a hand-held UV lamp at $360 \mathrm{~nm}$.

erasing process, a shadow mask was used again, and an acetonitrile solution of trifluoroacetic acid (TFA) was sprayed 
onto film. The nonfluorescent cyanide image disappeared, and the fluorescence of the cyanide-exposed region of the film was restored.

In this work, we have successfully designed and synthesized a colorimetric and fluorimetric molecular probe for sensing and signaling cyanide ions. The signal transduction mechanism was investigated by UV/vis absorption, emission, and NMR spectroscopy. The interaction between the chemosensor $\mathbf{3}$ and cyanide ions causes large changes in both color and fluorescence emission intensity.

The results obtained using poly(methyl methacrylate) (PMMA) polymer matrix demonstrate that the use of the trifluoroacetanilide group with novel BODIPY dyes opens new avenues for the sensing of materials in solid state. The

(13) Du, H.; Fuh, R. A.; Li, J.; Corkan, A.; Lindsey, J. S. Photochem. Photobiol. 1998, 68, 141-142. signaling of cyanide ions takes place near the red end of the visible spectrum, which is a distinct advantage. Further work on this type of compoud is expected to yield novel cyanidesensing platforms with practical utility. Work to that end is in progress in our laboratory.

Acknowledgment. This work was supported by Turkish Scientific and Technical Research Council (TUBITAK) and Turkish Academy of Sciences (TUBA). M.D.Y. thanks TUBITAK for a scholarship.

Supporting Information Available: Syntheses, experimental details, ${ }^{1} \mathrm{H}$ and ${ }^{13} \mathrm{C}$ NMR spectra and additional spectroscopic data. This material is available free of charge via the Internet at http://pubs.acs.org.

OL702823U 